\title{
Textbook of FORENSIC ODONTOLOGY
}

\section{Nitul Jain}

Publisher: Jaypee Brothers Medical Publishers (P) Ltd Language: English

ISBN: 978-93-5025-722-7

Edition: 1/e

Publish Year: 2013

Pages: 234

Price: $£ 36.00$

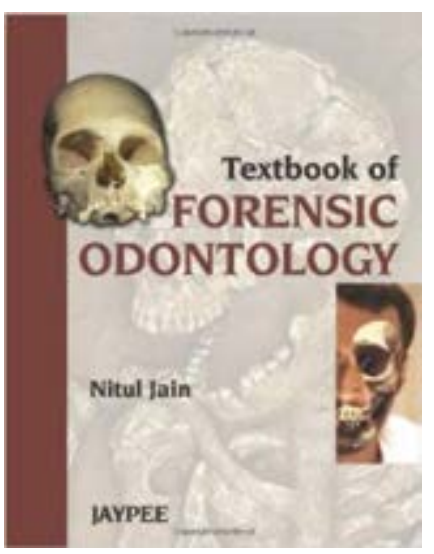

Forensic odontology is a branch of forensic medicine and deals with the proper examination, handling and presentation of dental evidence.

The "Textbook of Forensic Odontology" provides an overview of the subject with ten chapters. After an introduction to forensic sciences and the different branches, there follow the applications of forensic odontology. The individual chapters go through topics such as dental records, oral and maxillofacial radiology, age estimation, cheiloscopy, palatoscopy and forensic facial reconstruction. The last chapters discuss the identification of mass disaster victims, as well as victims of child abuse, neglect and domestic

violence. The "Textbook of Forensic Odontology" drafted by Dr. Nitul Jain and contributors, is a brief but comprehensive manual eloquently illustrated in more than 260 full color images and photographs; it is easy to understand and useful for the subject of oral pathology, oral medicine and forensic medicine. 